\title{
SUSTAINABILITY ASSESSMENT OF DIFFERENT NANOPARTICLE FOR HEAT EXCHANGER APPLICATIONS: AN INTUITIONISTIC FUZZY COMBINATIVE DISTANCE-BASED ASSESSMENT METHOD
}

\author{
Sunil Kumar \\ Faculty of Engineering and Technology, Shoolini University \\ Solan, H.P, 173229, India \\ Sandeep Kumar Gautam \\ Faculty of Engineering and Technology, Shoolini University \\ Solan, H.P, 173229, India \\ Ankush Kumar \\ Faculty of Engineering and Technology, Shoolini University \\ Solan, H.P, 173229, India
}

Rajesh Maithan*

Department of Mechanical Engineering, School of Engineering, University of Petroleum \& Energy Studies Bidholi, Dehradun- 248007, Uttarakhand, India, e-mail: rmaithani@ddn.upes.ac.in

\section{Anil Kumar}

Department of Mechanical Engineering, School of Engineering, University of Petroleum \& Energy Studies Bidholi, Dehradun- 248007, Uttarakhand, India, e-mail: rmaithani@ddn.upes.ac.in

Article history: Received 5 August 2021, Received in revised form 9 August 2021, Accepted 12 August 2021, Available online 12 August 2021

\begin{abstract}
The rate at which the conventional energy sources are depleting is a matter of concern, and there have been major attention on this to make the thermal systems environment friendly, efficient, economic, sustainable, technically reliable. Sustainability of five different types of nanoparticles (Ceramic, carbon based, metal based, polymeric, and lipid based) from the perspective of four aspects involving cost, efficiency, technicality and environmental effect, in heat exchangers has been assessed. The analysis is carried out using the intuitionistic fuzzy combative distance-based assessment (IFCODAS) method. In order to measure the sustainability of nanoparticles, a set of eleven evaluating criteria have been accredited on the basis of expert opinions and focus group meetings. By amalgamating the intuitionistic fuzzy set (IFS) theory as well as the use of distance-based assessment (CODAS) method, the IFCODAS method has permitted the decision-makers to rate the alternative five nanoparticles pertaining to each criterion. On the basis of the results obtained from IFCODAS method, it is observed that the carbon-based nanoparticles have an immense potential to provide significantly reliable and sustainable thermal system than other nanoparticles.
\end{abstract}

Keywords

heat transfer, nanoparticles, intuitionistic fuzzy set

\section{Introduction}

Every facet of life involves the usage of heat energy in certain forms and as per a definition, the amount of energy which is transferred between two substances at a different temperature is called heat $[1,2]$. The flow of energy occurs from the substance which is at a higher temperature to the substance which is at a lower temperature. Conduction, convection and radiation are the three basic mechanisms by which the heat transfer takes place $[3,4]$. Additionally, the heat transfer fluids' future lies in the nanofluids in several heat transfer applications, pertaining to the fact that they have been found to possess boosted thermo-physical properties which render them potentially expedient in voluminous applications in heat transfer. Various types of nanoparticles viz. metals $(C u, A g, A u)$, carbon 
nanotubes, oxide ceramics $\left(\mathrm{Al}_{2} \mathrm{O}_{3}, \mathrm{CuO}\right)$, carbide ceramics $(\mathrm{SiC}, \mathrm{TiC})$ and number of liquid like oil, ethylene glycol and water are examined $[5,6]$.

Akbari et al. [7] numerically studied the thermal behaviour of turbulent and laminar flow of water/ $\mathrm{Al}_{2} \mathrm{O}_{3}$ nanofluid having a volume fraction of $\varphi=0-4 \%$ of solid nanoparticles in Reynolds numbers in a range of 500 to 25000. The results reveals that for turbulent flow, the use of solid nanoparticles in higher volume fractions have a progresses heat transfer as compared to the laminar flow., Azmi, et al. [8]. Elamsa-ard Kiatkittipong [9] has investigated the heat transfer coefficients of $\mathrm{SiO}_{2} /$ water and $\mathrm{TiO}_{2} /$ water nanofluid up to $3 \%$ volume concentration flowing in a circular tube. It has been deduced from the investigation that the heat transfer enhancement gets inversely increased with twist ratio. The $\mathrm{SiO}_{2} /$ water nanofluid with a volume concentration of $3.0 \%$ delivers a heat transfer coefficient of $27.9 \%$ higher than water flow for the same twist ratio of five. Nonetheless, the value of heat transfer coefficient of $\mathrm{TiO}_{2}$ /water nanofluid evaluated at the same concentration has been found to be $11.4 \%$ greater than water for twist ratio of five. Chougule and Sahu [10] studied the $\mathrm{Al}_{2} \mathrm{O}_{3}$ /water and CNT/water nanofluids in a heat exchanger tube inserted with helical twisted tape and reported that CNT/water delivers higher thermal characteristics.

Eiamsa-ard and Wongcharee [11] analysed the thermal characteristics by integrated nanofluids with dual twisted-tapes in a micro-fin tube and reported that the selected idea delivers higher thermal performance factor. (Magesh Babu et al. [12], Hosseinnezhad et al. [13], Jafaryar et al. [14] reported that average $\mathrm{Nu}$ increases as the twist ratio decreases, because the counter-swirl flow twisted-tape along with increase in volume fraction of $\mathrm{Al}_{2} \mathrm{O}_{3}$ nanoparticles in the base fluid. Mohammadiun et al. [15] have conducted an experimental study on $\mathrm{Al}_{2} \mathrm{O}_{3}$ /ethylene glycol (EG) nanofluid turbulent flow through corrugated quipped with twisted tapes although Naik et al. [16] experimentally a plain tube and tube with twisted tape for thermal analysis purpose with water/propylene glycol based $\mathrm{CuO}$ nanofluids and reported higher performance using the inserts in the tube. Kumar et al. [17] determined the thermohydraulic behaviour of $\mathrm{Fe}_{3} \mathrm{O}_{4} /$ water nanofluids inside a double pipe Ubend and the result revealed there is enhancement of $N u$ by $38.75 \%$. Liu et al. [18] have surveyed the effect of algae on the combined toxicity of nano- $\mathrm{TiO}_{2}$ and lead $(\mathrm{Pb})$, while Deng et al. [19] have scrutinized the effects of $\mathrm{Zn}$-doped $\mathrm{TiO}_{2}$ nanoparticles and it has been explored that increasing the amount of $\mathrm{Zn}$ doping in the $\mathrm{TiO}_{2}$ film, the performance of the cell decreases, which has been ascribed to introducing a large number of $\mathrm{ZnO}$ clusters and producing more surface defects in the $\mathrm{TiO}_{2}$ film that act as electron-hole recombination centres.

In the recent past, the main consideration has been fixated on the usage of nanoparticles in the arena of structural nano ceramics, wear resistant coatings and functional nanomaterials for optoelectronics, photonics and bio-imaging D'Amato et al. [20]. have addressed the progress of doped and pure $\mathrm{TiO}_{2} \mathrm{NPs}_{\mathrm{S}}$ for applications in photocatalysis and DSSC electrodes fabrication Vollath et al. [21] fetched the potentials of synthesizing ceramic nanoparticles in a microwave plasma. Matsumoto et al. [22] have synthesized SiN-based ceramic nanoparticles by the crosslinking and pyrolysis of the micelles. Such sort of ceramic particles are anticipated to be germane to catalysts, surface modification, and electric device preparation.

A model glucose biosensor has been developed by Shen et al. [23] using immobilization of glucose oxidase on the iridium-containing carbon working electrode's surface covalently by the usage of glutaraldehyde, and have signified its applicability for the progression of single usage, disposable electrochemical biosensors formulated on $\mathrm{H}_{2} \mathrm{O}_{2}$ detection with the usage of an oxidase. (Zhou et.al [24]; Ngoy et al. [25] and Zhang et al. [26] have grafted a long chain polymer along with a diamine in order to offer a large $\mathrm{CO}_{2}$ anchoring site for the formation of carbamate, covering multi-walled carbon nanotubes (MWNTs) in order to augment the surface area as well as the pore volume. It has been undoubtedly established by these studies that the shape of carbon nano materials is correlated with their toxicity. He et al. [27] have proposed that NPs with slight negative charges and particle size of $150 \mathrm{~nm}$ were found to be more efficiently. These results could further serve as a guideline in the rational design of drug nano carriers with maximized therapeutic efficiency or worth.

This present work focused on developing a multi-criteria decision structure (IFCODAS) for assessment of sustainability using varying nanoparticle types in heat exchangers. This system integrates a fuzzy set based weighting method that inculcates the preference/views of the decision-makers in to get the dominance of evaluation criteria. The used numerical model determines the dominance of the system as well as the operating parameters in a selected range. The numerical model designed is used to determine the dominance of a nanofluid out of number of fluids used on the basis of different criterion viz. sustainability, environmental aspect, reliability, efficiency aspect, technical aspect, etc. 
Fuzzy and intuitionistic fuzzy set

Definition1. Fuzzy sets $(F S)[28,29]$.

The set $Z$ which is composed by $x$, and a fuzzy set $\tilde{a}$ which is defined by a membership function $\mu_{\tilde{a}}(x)$, measuring belonging of $x$ to $\propto . \mu_{\tilde{a}}(x)$ signifies the membership of $x$ in $\tilde{a}$,

$$
\alpha=\left\{\left(x, \mu_{\approx a}(x) \mid x \in Z\right\}\right.
$$

Definition2. Intuitionistic fuzzy set (IFS) [29]

If $Z$ be the collection of objects $x$, and $\beta \in Z$ be a fixed set, then intuitionistic fuzzy set $\beta$ be defined as:

$$
\beta=\left\{\left(x, \mu_{\beta}(x), \vartheta_{\beta}(x)\right) \mid x \in Z\right.
$$

Where $\mu_{\beta}(x): Z \rightarrow[0,1], x \in Z \rightarrow \mu_{\beta}(x) \in[0,1]$ represents the degree of membership of the member $x \in Z$ to the set $\beta$, and $\vartheta_{\beta}(x): Z \rightarrow[0,1], x \in Z \rightarrow \vartheta_{\beta}(x) \in[0,1]$ is non-membership degree of the member $\mathrm{x} \in Z$ to the set $\beta$. $\mu_{\beta}$ and $\vartheta_{\beta}(x)$ generally placates $0 \leq \mu_{\beta}(x)+\vartheta_{\beta}(x) \leq 1, \forall \mathbf{x} \in Z$. In addition to membership and nonmembership degree, an indeterminacy degree, called "hesitancy degree" purported of $x$ to the set $\beta$, which is quite unalike the numbers $\mu_{\beta}(x)$ and $\vartheta_{\beta}(x)$ signifying the membership and non-membership degree of the member $\mathrm{x} \in \mathrm{Z}$ to the set $\beta$, thus indeterminacy degree measure of $\mathrm{x} \in \mathrm{Z}$ to the set $\beta$ is defined as:

$$
\pi_{\beta}(x)=1-\mu_{\beta}(x)-\vartheta_{\beta}(x), x \in X
$$

Consequently, an intuitionistic fuzzy number $\beta$, customarily be denoted by $\beta=\left(\mu_{\beta}, \vartheta_{\beta}, \pi_{\beta}\right)$ which encompassed the membership, non-membership as well as indeterminacy degree.

Definition3. Arithmetical operations [30].

Let $\gamma=\left(\mu_{\gamma}, \vartheta_{\gamma}, \pi_{\gamma}\right)$ and $\beta=\left(\mu_{\beta}, \vartheta_{\beta}, \pi_{\beta}\right)$ are the $\beta$. The arithmetical operations amongst these two numbers can be depicted as:

Addition

$$
\begin{gathered}
(\nu \oplus \beta)=\left(\mu_{\gamma}, \vartheta_{\gamma}, \pi_{\gamma}\right) \oplus\left(\mu_{\beta}, \vartheta_{\beta}, \pi_{\beta}\right) \\
=\left(\mu_{\gamma}+\mu_{\beta}-\mu_{\gamma} \mu_{\beta}, \vartheta_{\gamma} \vartheta_{\beta}, 1+\mu_{\gamma} \mu_{\beta}-\mu_{\gamma}-\mu_{\gamma}-\vartheta_{\gamma} \vartheta_{\beta}\right) \\
\bigoplus_{j=1}^{n} \gamma_{j}=\oplus_{j=1}^{n}\left(\mu_{\gamma_{j}}, \vartheta_{\gamma_{j}}, \pi_{\gamma_{j}}\right)=\left(1-\prod_{j=1}^{n}\left(1-\mu_{\gamma_{j}}\right), \prod_{j=1}^{n} \vartheta_{\gamma_{j}}, \prod_{j=1}^{n}(1-\right. \\
\left.\left.\mu_{\gamma_{j}}\right)-\prod_{j=1}^{n} \vartheta_{\gamma_{j}}\right)
\end{gathered}
$$

Multiplication

$$
\begin{gathered}
\nu \otimes \beta=\left(\mu \_\gamma, \vartheta \_\gamma, \pi \_\gamma\right) \otimes\left(\mu \_\beta, \vartheta \_\beta, \pi \_\beta\right)=\left(\mu \_\gamma \mu \_\beta, \vartheta \_\gamma+\vartheta_{-} \beta-\vartheta \_\gamma \vartheta \_\beta, 1+\vartheta \_\gamma \vartheta \_\beta-\mu \_\gamma \mu \_\beta-\vartheta \_\gamma-\right. \\
\left.\vartheta_{-} \beta\right) \\
\otimes_{j=1}^{n} \gamma_{j}=\otimes_{j=1}^{n}\left(\mu_{\gamma_{j}}, \vartheta_{\gamma_{j}}, \pi_{\gamma_{j}}\right)=\left(\prod_{j=1}^{n} \mu_{\mu_{\gamma_{j}}}, \prod_{j=1}^{n}\left(1-\vartheta_{\gamma_{j}}\right), 1-\prod_{j=1}^{n} \mu_{\gamma_{j}}-\prod_{j=1}^{n}\left(1-\vartheta_{\gamma_{j}}\right)\right) \\
\lambda \_\gamma=\left(1-\left(1-\mu \_\gamma\right) \wedge \lambda \llbracket, \llbracket\left(\vartheta \_\gamma\right) \rrbracket \wedge \lambda,\left(1-\mu \_\gamma\right) \rrbracket \wedge \lambda-\left(\llbracket \vartheta \_\gamma\right) \rrbracket \wedge \lambda\right)
\end{gathered}
$$

where $\lambda$ called as crisp number.

Definition4. Geometrical distance [31].

The distance between intuitionistic fuzzy sets $\gamma=\left(\mu_{\gamma}, \vartheta_{\gamma}, \pi_{\gamma}\right)$, and $\beta=\left(\mu_{\beta}, \vartheta_{\beta}, \pi_{\beta}\right)$ is determined using Equation (9) and Equation (10).

The harmonic distance:

$$
\begin{gathered}
d(\gamma, \beta)=\sum_{j=1}^{n}\left(\left|\mu_{\gamma}\left(x_{j}\right)-\mu_{\beta}\left(x_{j}\right)\right|+\left|\vartheta_{\gamma}\left(x_{j}\right)-\vartheta_{\beta}\left(x_{j}\right)\right|+\mid \pi_{\gamma}\left(x_{j}\right)-\right. \\
\left.\pi_{\beta}\left(x_{j}\right) \mid\right)
\end{gathered}
$$


The Euclidean distance:

(10)

$$
d(\gamma, \beta)=\sqrt{\sum_{j=1}^{n}\left(\mu_{\gamma}\left(x_{j}\right)-\mu_{\beta}\left(x_{j}\right)\right)^{2}+\left(\vartheta_{\gamma}\left(x_{j}\right)-\vartheta_{\beta}\left(x_{j}\right)\right)^{2}+\left(\pi_{\beta}\left(x_{j}\right)-\pi_{\beta}\left(x_{j}\right)\right)^{2}}
$$

Definition5. Score $\left(S_{\gamma}\right)$ and accuracy $\left(H_{\gamma}\right)$ degree of the intuitionistic fuzzy set [32]

The score $\left(S_{\gamma}\right)$ and accuracy $\left(H_{\gamma}\right)$ degree determined by using Equations (11) and (12), respectively.

$$
\begin{aligned}
& S_{\gamma}=\mu_{\gamma}-\vartheta_{\gamma} \\
& H_{\gamma}=\mu_{\gamma}+\vartheta_{\gamma}
\end{aligned}
$$

\section{Methodology}

Present study espouses the methodology which consists of two parts. The first part is based on the criteria for sustainability assessments of five different types of nanoparticles, and the second part covered Intuitionistic fuzzy multi-criteria decision-making method (IFMCDM). These two parts are presented as follows:

\section{Criteria for sustainability assessment of different types of nanoparticles}

Based on the experts' views, literature review and focus group meetings, eleven indexes, related to four aspects involving cost $(C)$, efficiency $(E)$, technical $(T)$ and environmental effect (EE) have been accredited as the evaluation criteria for sustainability assessment of different types of nanoparticles. Related to cost aspect these indexes are capital cost (C1), operating cost (C2) and durability cost (C3), whereas, with respect to efficiency aspect these indexes are thermal efficiency (E1), effective efficiency (E2) and exergetic efficiency (E3). In the point of view of the technical aspect, the indexes are technical complexity (T1) and technical reliability (T2), and for environment aspect the indexes finalized, are risk to ecosystem (EE1), wastage utilization (EE2), and toxic effect on environment (EE3). The criteria capital cost, operating cost, durability cost, technical complexity, risk to ecosystem and toxic effect on environment have been categorized as cost criteria (smaller the better) and rest have been categorized as benefit criteria (the larger the better).

Intuitionistic fuzzy multi-criteria decision making (IFMCDM):

A novel $M C D M$ is setup for sustainability ranking of different nanoparticles by combining the $I A H P$ and IFCODAS. The projected MCDM method is shown in Fig.1. The IAHP figure out the weightage of the sustainability assessment criteria for an energy storage technique facilitates. The Combinative Distance-based Assessment Method (CODAS) is used for rating intuitionistic fuzzy numbers for different nanoparticle. 


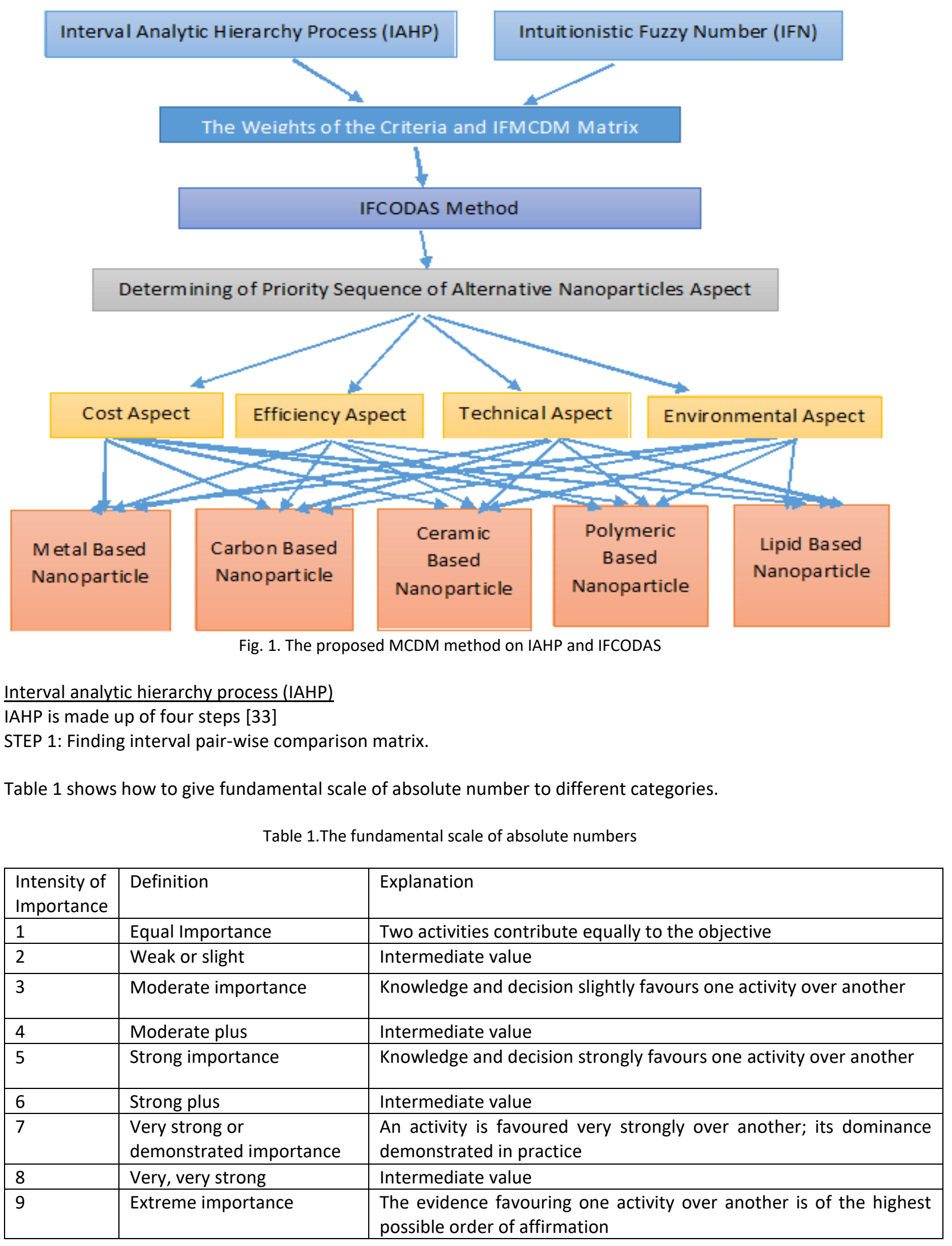


The administrators used a 9-scale system to set up the couplet juxtaposition matrix. Assuming that there are ' $\mathrm{n}$ ' number of matrix $\left[M_{1} \cdots \cdots M_{n}\right]$ which required to identify proportional weights. In an attempt to begin the pair wise comparison matrix, the conventional AHP technique has utilized the numbers from 1-9 often with their reciprocal for contrasting each doublet of factors. Occasionally, an individual number is unable to picturize the relative weight. For instance, there is no individual number which can depict the parallel priority of matrix to next one, while the administrator held the view that parallel importance of the matrix to next one lies between moderate and equal importance. So the interval number $(1,3)$ can be employed to figure out the specific situation. The interval-comparison is calculated for ' $n$ ' matrix as suggested in literature [34].

$$
\begin{array}{cccc}
M_{1} & M_{2} & \ldots & M_{n} \\
M_{1} 1 & {\left[q_{12}^{L}, q_{12}^{U}\right]} & \ldots & {\left[q_{1 n}^{L}, q_{1 n}^{U}\right]} \\
Q^{ \pm}=M_{2}\left[q_{21}^{L}, q_{21}^{U}\right] & 1 & \ldots & {\left[q_{2 n}^{L}, q_{2 n}^{U}\right]} \\
\vdots & \vdots & \ddots & \vdots \\
M_{n}\left[q_{n 1}^{L}, q_{n 1}^{U}\right] & {\left[q_{n 2}^{L}, q_{n 2}^{U}\right]} & \ldots & 1
\end{array}
$$

The relational significance of the $j^{\text {th }}$ metric as compared to $i^{\text {th }}$ metric is explored by following equation suggested by Saaty [34].

$$
\frac{1}{\left[q_{i j}^{L}, q_{i j}^{U}\right]}=\left[\frac{1}{q_{i j}^{U}}, \frac{1}{q_{i j}^{L}}\right], i, j=1,2, \ldots, n
$$

Step 2: Decomposing the interval pair-wise comparison matrix [33].

The comparison of interval pair-wise matrix in equation (14) is split in two nonnegative matrices, as given in equations (15-16).

$$
\begin{gathered}
Q_{L}=\left[\begin{array}{ccc}
1 & \cdots & q_{1 n}^{L} \\
\vdots & \ddots & \vdots \\
1 / q_{n 1}^{U} & \cdots & 1
\end{array}\right] \\
Q_{U}=\left[\begin{array}{ccc}
1 & \cdots & q_{1 n}^{U} \\
\vdots & \ddots & \vdots \\
1 / q_{n 1}^{L} & \cdots & 1
\end{array}\right]
\end{gathered}
$$

The finding of weightages for the matrices presented in equations (15-16) is carried out by the geometric mean method and the weight vectors computed are shown in equations (17-18), respectively.

$$
\begin{aligned}
& W_{L}=\left[\begin{array}{llll}
\omega_{1}^{L} & \omega_{2}^{L} & \ldots & \omega_{n}^{L}
\end{array}\right] \\
& W_{U}=\left[\begin{array}{llll}
\omega_{1}^{U} & \omega_{2}^{U} & \ldots & \omega_{n}^{U}
\end{array}\right]
\end{aligned}
$$

STEP 3: Finding the interval weights [33].

For each matrix, interval weights are computed using Equations (19-21) as follows

$$
\begin{aligned}
& \mathrm{s}=\sqrt{\sum_{j=1}^{n} \frac{1}{\sum_{i=1}^{n} q_{i j}^{+}}} \\
& \mathrm{t}=\sqrt{\sum_{j=1}^{n} \frac{1}{\sum_{i=1}^{n} q_{i j}^{-}}}
\end{aligned}
$$


The weight vectors calculated using Equations (15-16) are represented by $\mathrm{W}_{\mathrm{L}}$ and $\mathrm{W}_{\mathrm{U}}$, respectively, whereas $\omega_{\mathrm{j}}^{\mathrm{L}}$ and $\omega_{\mathrm{j}}^{\mathrm{U}}$ are the weights of the $j^{\text {th }}$ metric in $\mathrm{W}_{\mathrm{L}}$ and $\mathrm{W}_{\mathrm{U}}$, respectively,

$$
\omega_{\mathrm{j}}^{ \pm}=\left[\mathrm{k} \omega_{\mathrm{j}}^{\mathrm{L}} \mathrm{m} \omega_{\mathrm{j}}^{\mathrm{U}}\right]
$$

where $\omega_{j}^{ \pm}$gives interval weight of the $j^{\text {th }}$ matrix.

STEP 4: Finding the crisp weights of the matrices [35].

The possibilities of $\omega_{j}^{ \pm}$to be more than $\omega_{r}^{ \pm}$can be determine by Equation (22) in accordance with equation (21).

$$
p_{j r}=p\left(\omega_{j}^{ \pm} \geq \omega_{r}^{ \pm}\right)=\max \left\{1-\max \left[\frac{m \omega_{r}^{U}-k \omega_{j}^{L}}{m \omega_{r}^{U}-k \omega_{r}^{L}+m \omega_{j}^{U}-k \omega_{j}^{L}}\right], 0\right\}
$$

After the comparison of each pair of weights, the possibility matrix, determined by Equation (23).

$$
\mathrm{M}=\left[\begin{array}{ccc}
M_{11} & \cdots & M_{1 n} \\
\vdots & \ddots & \vdots \\
M_{n 1} & \cdots & M_{n n}
\end{array}\right]
$$

The crisp weight $\left(\omega_{j}\right)$ of each matrix is determined by Equation (24)

$$
\omega_{j}=\frac{\sum_{r=1}^{n} p_{j r}+\frac{n}{2}-1}{n(n-1)}
$$

Intuitionistic fuzzy combinative distance-based assessment method (IFCODAS):

Euclidian and taxicab distance from the negative idol solution can weigh the overall performance with the help of CODAS. Nonetheless, ambiguous and vague human decrees cannot be clarified with traditional CODAS. With the combination of CODAS and Intuitionist fuzzy method, the new IFCODAS method has been used. Ghorabaee et al. [36]. Here IFCODAS was specified as:

STEP 1: Assume $n$ matrices $\left(a_{1} \cdots \cdots a_{n}\right)$ is used to evaluate the $m$ alternative $\left(A_{1} \cdots \cdots A_{m}\right)$. The administrators were requested to grade the substitutes with respect to each other through linguistic variables including (EP, UP, P, MP, F, MG, G, VG, EG). According to table 2 linguistic variables are shifted to intuitionist fuzzy numbers.

Table 2. Linguistic variables and their intuitionistic fuzzy numbers

\begin{tabular}{|l|l|l|}
\hline Linguistic variables & Abbreviation & Intuitionistic fuzzy numbers \\
\hline Extremely good & EG & $(0.95,0.05,0)$ \\
\hline Very good & VG & $(0.85,0.10,0.05)$ \\
\hline Good & G & $(0.75,0.15,0.10)$ \\
\hline Medium good & MG & $(0.65,0.25,0.10)$ \\
\hline Fair & F & $(0.50,0.40,0.10)$ \\
\hline Medium poor & MP & $(0.35,0.55,0.10)$ \\
\hline Poor & P & $(0.25,0.65,0.10)$ \\
\hline Very Poor & VP & $(0.15,0.80,0.05)$ \\
\hline Extremely Poor & EP & $(0.05,0.95,0)$ \\
\hline
\end{tabular}

So the intuitionist fuzzy administrator making matrix may be determined as depicted in Equation (25) 
(25)

$$
\mathrm{D}=\begin{array}{ccccc}
A_{1} & \left(\mu_{11}^{x}, \vartheta_{11}^{x}, \pi_{11}^{x}\right) & \left(\mu_{12}^{x}, \vartheta_{12}^{x}, \pi_{12}^{x}\right) & \ldots & \left(\mu_{1 n}^{x}, \vartheta_{1 n}^{x}, \pi_{1 n}^{x}\right) \\
A_{2} & \left(\mu_{21}^{x}, \vartheta_{21}^{x}, \pi_{21}^{x}\right) & \left(\mu_{22}^{x}, \vartheta_{22}^{x}, \pi_{22}^{x}\right) & \ldots & \left(\mu_{2 n}^{x}, \vartheta_{2 n}^{x}, \pi_{2 n}^{x}\right) \\
\vdots & \vdots & \vdots & \ddots & \vdots \\
A_{m} & \left(\mu_{m 1}^{x}, \vartheta_{m 1}^{x}, \pi_{m 1}^{x}\right) & \left(\mu_{m 2}^{x}, \vartheta_{m 2}^{x}, \pi_{m 2}^{x}\right) & \ldots & \left(\mu_{m n}^{x}, \vartheta_{m n}^{x}, \pi_{m n}^{x}\right)
\end{array}
$$

STEP2: The weighted intuitionistic fuzzy decision-making matrices are determined using Equations (26) and (27).

(26)

$$
\begin{aligned}
& \begin{array}{llll}
M_{1} & M_{2} & \ldots & M_{n}
\end{array} \\
& A_{1} \omega_{1}\left(\mu_{11}^{x}, \vartheta_{11}^{x}, \pi_{11}^{x}\right) \quad \omega_{2}\left(\mu_{12}^{x}, \vartheta_{12}^{x}, \pi_{12}^{x}\right) \quad \ldots \quad \omega_{n}\left(\mu_{1 n}^{x}, \vartheta_{1 n}^{x}, \pi_{1 n}^{x}\right) \\
& \mathrm{WD}=A_{2} \omega_{1}\left(\mu_{21}^{x}, \vartheta_{21}^{x}, \pi_{21}^{x}\right) \quad \omega_{2}\left(\mu_{22}^{x}, \vartheta_{22}^{x}, \pi_{22}^{x}\right) \quad \ldots \quad \omega_{n}\left(\mu_{2 n}^{x}, \vartheta_{2 n}^{x}, \pi_{2 n}^{x}\right) \\
& A_{m} \omega_{1}\left(\mu_{m 1}^{x}, \vartheta_{m 1}^{x}, \pi_{m 1}^{x}\right) \quad \omega_{2}\left(\mu_{m 2}^{x}, \vartheta_{m 2}^{x}, \pi_{m 2}^{x}\right) \quad \ldots \quad \omega_{n}\left(\mu_{m 2}^{x}, \vartheta_{m 2}^{x}, \pi_{m 2}^{x}\right) \\
& \begin{array}{ccccc}
M_{1} & M_{2} & \ldots & M_{n}
\end{array} \\
& A_{1}\left(\mu_{11}, \vartheta_{11}, \pi_{11}\right) \quad\left(\mu_{12}, \vartheta_{12}, \pi_{12}\right) \quad \ldots \quad\left(\mu_{1 n}, \vartheta_{1 n}, \pi_{1 n}\right) \\
& =A_{2}\left(\mu_{21}, \vartheta_{21}, \pi_{21}\right) \quad\left(\mu_{22}, \vartheta_{22}, \pi_{22}\right) \quad \ldots \quad\left(\mu_{2 n}, \vartheta_{2 n}, \pi_{2 n}\right) \\
& A_{m}\left(\mu_{m 1}, \vartheta_{m 1}, \pi_{m 1}\right) \quad\left(\mu_{m 2}, \vartheta_{m 2}, \pi_{m 2}\right) \quad \ldots \quad\left(\mu_{m n}, \vartheta_{m n}, \pi_{m n}\right)
\end{aligned}
$$

STEP3: The negative ideal solution (NIS) is determined by Equations (28-32) .

$$
\begin{gathered}
\mathrm{NIS}=\left(\mu_{j}, \vartheta_{j}, \pi_{j}\right), j=1,2,3, \ldots, n \\
\mathrm{t}=\arg _{i} \min \left(\mu_{i j}\right) \\
\mu_{j}=\mu_{t j} \\
\vartheta_{j}=\vartheta_{t j} \\
\pi \_1-\mu_{-} \mathrm{tj}-\vartheta_{-} \mathrm{tj}
\end{gathered}
$$

STEP-4: The Euclidean (E) and harmonic $(H)$ distances are calculated using Equations $(33,34)$.

$$
\frac{\mathrm{E}\left(w d_{i j}, N I S_{J}\right)=}{\sqrt{\left.\frac{1}{2} \sum_{j=1}^{n}\left(\mu_{i j}-\mu_{j}\right)^{2}+\left(\vartheta_{i j}-\vartheta_{j}\right)^{2}+\left(\pi_{i j}-\pi_{j}\right)^{2}\right]}}
$$

$$
\mathrm{H}\left(w d_{i j}, N I S_{J}\right)=\frac{1}{2} \sum_{J=1}^{N}\left(\left|\mu_{i j}-\mu_{j}\right|+\left|\vartheta_{i j}-\vartheta_{j}\right|+\left|\pi_{i j}-\pi_{j}\right|\right)
$$

STEP 5: The relative assessment matrix $(R)$ is determined by using Equations (35-37).

$$
\begin{gathered}
\mathrm{R}=\left\{r_{i k}\right\} \\
r_{i k}=\left[E\left(w d_{i j}, N\right)-E\left(w d_{k j}, N I S_{j}\right)\right]+\emptyset\left[E\left(w d_{i j}, N I S_{j}\right)-E\left(w d_{k j}, N I S_{j}\right)\right] \\
\times\left[H\left(w d_{i j}, N I S_{j}\right)-H\left(w d_{k j}, N I S_{j}\right)\right]
\end{gathered}
$$




$$
\emptyset\left[E\left(w d_{i j}, N I S_{j}\right)-E\left(w d_{k j}, N I S_{j}\right)\right]=\left\{\begin{array}{c}
1 \text { if }-\tau \leq E\left(w d_{i j}, N I S_{j}\right)-E\left(w d_{k j}, N I S_{j}\right) \leq \tau \\
0 \text { if others }
\end{array}\right.
$$

STEP 6: The final assessment score $\left(S_{i}\right)$ of each alternative is calculated using Equation 38.

$$
S_{i}=\sum_{k=1}^{m} r_{i k}
$$

Case Study:

Five nanoparticles viz. metal based nanofluids (A1), carbon-based nanoparticles (A2), ceramic based nanoparticles (A3), polymeric nanoparticles (A4), and lipid-based nanoparticles (A5), by the planned intuitionistic fuzzy multi-criteria decision-making method have been studied in the present study. These five nanoparticles can be designated as:

Metal Based Nanoparticles: Metal nanoparticles are thriving from metal precursors and manufactured by chemical, electrochemical, or photochemical method. The metal nanoparticles include gold ( $\mathrm{Au}$ ), nickel (Ni), silver $(\mathrm{Ag})$, zinc oxide $(\mathrm{ZnO})$, silica $\left(\mathrm{SiO}_{2}\right)$, and titanium dioxide $\left(\mathrm{TiO}_{2}\right)$ etc.

Carbon Nanoparticles: Carbon nanoparticles are highly advantageous in order to augment the crack initiation of energy threshold to advance impact capacity and post impact behaviour. It consists of carbon nanotubes (CNTs), zigzag nanotubes, and chiral carbon nanotubes.

Ceramic Nanoparticles: These are inorganic solid build-up of carbonates, carbides, oxides and phosphates with rich chemical inertness and heat resistances properties.

Polymeric Nanoparticles: They are organic based nanoparticles with nanosphere or nano capsular shaped structure. The most widely used polymeric are polylactide, polylactide-polyglycolide copolymers etc.

Lipid Nanoparticles: They are embraced of solid core which is designed of metrics and lipid accommodates soluble lipophilic molecules. Their shape is spherical while diameter varies from $10-100 \mathrm{~nm}$.

Out of four categories of assessment aspects (cost, efficiency, technical and environmental effect) the eligibility have been engaged for sustainability estimate capital cost (C1), operating cost (C2), and durability cost (C3) in cost aspect (C), thermal efficiency (E1), effective efficiency (E2), and exergetic efficiency in efficiency aspect (E), technical complexity (T1), technical reliability (T2), in technical aspect (T), and risk to ecosystem (EE1), wastage utilization(EE2), toxic effect on environment (EE3) in environment aspect (EE). The weight of four criteria and categories has been firstly identified by IAHP. The following steps of IAHP have been described through example: Step 1: Weights of four assessment aspects can be firstly identified through interval pair-wise comparison matrix as shown in Table no. 3.

Table 3 Interval pair-wise comparison matrix for determining categories weight

\begin{tabular}{|l|l|l|l|l|}
\hline & Cost & Efficiency & Technology & Environment \\
\hline $\mathrm{C}$ & $(1,1)$ & $(3,7)$ & $(1,3)$ & $(5,7)$ \\
\hline $\mathrm{E}$ & $(1 / 7,1 / 3)$ & $(1,1)$ & $(1 / 5,1 / 2)$ & $(3,5)$ \\
\hline $\mathrm{T}$ & $(1 / 3,1)$ & $(2,5)$ & $(1,1)$ & $(3,7)$ \\
\hline $\mathrm{EE}$ & $(1 / 7,1 / 5)$ & $(1 / 5,1 / 3)$ & $(1 / 7,1 / 3)$ & $(1,1)$ \\
\hline
\end{tabular}

Step 2: According to Table no. 3 the result of two crisp nonnegative matrices can be identified and expressed in Equation (39) and Equation (40). 
(39)

$$
\mathrm{P}_{\mathrm{L}}=\left[\begin{array}{llll}
p_{11}^{-} & p_{12}^{-} & p_{13}^{-} & p_{14}^{-} \\
p_{21}^{-} & p_{22}^{-} & p_{23}^{-} & p_{24}^{-} \\
p_{31}^{-} & p_{32}^{-} & p_{33}^{-} & p_{34}^{-} \\
p_{41}^{-} & p_{42}^{-} & p_{43}^{-} & p_{44}^{-} \\
& & &
\end{array}\right]=\left[\begin{array}{llll}
1 & 3 & 1 & 5 \\
1 / 7 & 1 & 1 / 5 & 3 \\
1 / 3 & 2 & 1 & 3 \\
1 / 7 & 1 / 5 & 1 / 7 & 1 \\
& & &
\end{array}\right]
$$

(40)

$$
\mathrm{P}_{\mathrm{U}}=\left[\begin{array}{llll}
p_{11}^{+} & p_{12}^{+} & p_{13}^{+} & p_{14}^{+} \\
p_{21}^{+} & p_{22}^{+} & p_{23}^{+} & p_{24}^{+} \\
p_{31}^{+} & p_{32}^{+} & p_{33}^{+} & p_{34}^{+} \\
p_{41}^{+} & p_{42}^{+} & p_{43}^{+} & p_{44}^{+} \\
& & &
\end{array}\right]=\left[\begin{array}{llll}
1 & 7 & 3 & 7 \\
1 / 3 & 1 & 1 / 2 & 5 \\
1 & 5 & 1 & 7 \\
1 / 5 & 1 / 3 & 1 / 3 & 1 \\
& & &
\end{array}\right]
$$

By the above matrices, weight $\mathrm{W}_{\mathrm{L}}$ and $W_{U}$ can be found by the geometric-method and represented in Equation (41) and Equation (42).

$$
\begin{aligned}
& W_{L}=\{0.4862,0.1462,0.3013,0.0662\} \\
& W_{-} U=\{0.4726,0.1401,0.3316,0.0558\}
\end{aligned}
$$

Step 3: The s and $t$ are determined from Equation (43) and Equation (44) respectively.

(43)

$$
\begin{aligned}
\mathrm{s}=\sqrt{\sum_{j=1}^{4} \frac{1}{\sum_{i=1}^{4} p_{i j^{+}}}} & =\sqrt{\frac{15}{38}+\frac{3}{40}+\frac{6}{29}+\frac{1}{20}} \\
= & 0.8524
\end{aligned}
$$

$$
\mathrm{t}=\sqrt{\sum_{j=1}^{4} \frac{1}{\sum_{i=1}^{4} p_{i j^{-}}}}=\sqrt{\frac{21}{34}+\frac{5}{31}+\frac{35}{82}+\frac{1}{12}}=
$$

Equations (45) to (48) represents the results of four assessment aspects of energy storage technologies of interval weights sustainability of Equation (21). 
(45)

$$
\begin{aligned}
& W_{C}^{ \pm}=\left\{\begin{array}{lll}
0.8524 \times 0.4862 & 1.1354 \times 0.4726
\end{array}\right\}=\left\{\begin{array}{ll}
0.4145 & 0.5365
\end{array}\right\} \\
& W_{E}^{ \pm}=\left\{\begin{array}{ll}
0.8524 \times 0.14621 .1354 \times 0.1401
\end{array}\right\}= \\
& \{0.12460 .1591\} \\
& \quad W_{-} T^{\wedge \pm}=\left\{\begin{array}{ll}
0.8524 \times 0.3013 & 1.1354 \times 0.3316
\end{array}\right\}=\left\{\begin{array}{ll}
0.2568 & 0.3764
\end{array}\right\} \\
& W_{E E}^{ \pm}=\left\{\begin{array}{lll}
0.8524 \times 0.06621 .1354 \times 0.0558
\end{array}\right\}=\left\{\begin{array}{lll}
0.0564 & 0.0634
\end{array}\right\}
\end{aligned}
$$

Step 4: By analysing the weight of each pair of division from Equation (22), the features of the possibility matrix are found. Assume that the possibility of $W_{E}^{ \pm}$be more than $W_{C}^{ \pm}$as an example:

(49)

$$
\begin{aligned}
& P\left(W_{E}^{ \pm} \geq W_{C}^{ \pm}\right)=\operatorname{Max}\left\{1-\max \left[\frac{W_{E}{ }^{U-W} C_{C^{L}}}{W_{E}^{U-W_{E}}{ }_{E^{L}+W_{C}}{ }^{U-W_{C}}}, 0\right], 0\right\} \\
& P\left(W_{E 2}^{ \pm} \geq W_{C 1}^{ \pm}\right)=\operatorname{Max}\left\{1-\max \left[\frac{0.1591-.04145}{0.1591-0.1246+0.5365-0.4145}, 0\right], 0\right\}=0
\end{aligned}
$$

In correspondingly, Equation (50) presents the results of possibility matrix.

(50)

$$
M=\left[\begin{array}{ccccc} 
& C & E & T & E E \\
C & 0.5000 & 1.0000 & 1.0000 & 1.0000 \\
E & 0 & 0.5000 & 0 & 1.0000 \\
T & 0 & 1.0000 & 0.5000 & 1.0000 \\
E E & 0 & 0 & 0 & 0.5000
\end{array}\right]
$$

According to Equation (51) the results of crisp weight of each metric are shown in Equations (51) to (54)

(51)

$$
W_{C}=\frac{\sum_{r=1}^{4} M_{1 r}+\frac{n}{2}-1}{n(n-1)}=\frac{0.5000+1.0000+1.0000+1.0000+\frac{4}{2}-1}{4(4-1)}=0.3570
$$

$$
W_{E}=\frac{\sum_{r=1}^{4} M_{2 r}+\frac{n}{2}-1}{n(n-1)}=\frac{0+0.5000+0+1.0000+\frac{4}{2}-1}{4(4-1)}=0.2083
$$

$$
W_{T}=\frac{\sum_{r=1}^{4} M_{3 r}+\frac{n}{2}-1}{n(n-1)}=\frac{0+1.0000+0.5000+1.0000+\frac{4}{2}-1}{4(4-1)}=0.2917
$$

$$
W_{E E}=\frac{\sum_{r=1}^{4} M_{4 r}+\frac{n}{2}-1}{n(n-1)}=\frac{0+0+0+0.5000+\frac{4}{2}-1}{4(4-1)}=0.1250
$$

$0.3570,0.2083,0.2917$, and 0.1250 , respectively shows the weights of the cost, efficiency, technological, and environmental effect assessment aspects. Likewise, Tables 4-7 depict the interval pair-wise comparison matrix of weights for each criterion. 
Table 4. The cost aspect weights of the three criteria's

\begin{tabular}{|l|l|l|l|}
\hline & C1 & C2 & C3 \\
\hline C1 & $(1,1)$ & $(1 / 3,1)$ & $(3,5)$ \\
\hline C2 & $(1,2)$ & $(1,1)$ & $(1,3)$ \\
\hline C3 & $(1 / 5,1 / 3)$ & $(1 / 3,1)$ & $(1,1)$ \\
\hline Weight & 0.3333 & 0.5000 & 0.1667 \\
\hline
\end{tabular}

Table 5. The efficiency aspect weights of the three criteria's

\begin{tabular}{|l|l|l|l|}
\hline & E1 & E2 & E3 \\
\hline E1 & $(1,1)$ & $(1 / 2,1)$ & $(3,5)$ \\
\hline E2 & $(1,2)$ & $(1,1)$ & $(1,3)$ \\
\hline E3 & $(1 / 5,1 / 3)$ & $(1 / 3,1)$ & $(1,1)$ \\
\hline Weight & 0.3333 & 0.5000 & 0.1667 \\
\hline
\end{tabular}

Table 6. The technical aspect weights of the two criteria's

\begin{tabular}{|l|l|l|}
\hline & T1 & T2 \\
\hline T1 & $(1,1)$ & $(1,5)$ \\
\hline T2 & $(1 / 5,1)$ & $(1,1)$ \\
\hline Weight & 0.750 & 0.250 \\
\hline
\end{tabular}

Table 7. The weights of the three criteria of environmental effect aspect

\begin{tabular}{|l|l|l|l|}
\hline & EE1 & EE2 & EE3 \\
\hline EE1 & $(1,1)$ & $(1 / 5,1)$ & $(1 / 3,1)$ \\
\hline EE2 & $(1,5)$ & $(1,1)$ & $(1 / 4,1 / 2)$ \\
\hline EE3 & $(1,3)$ & $(2,4)$ & $(1,1)$ \\
\hline Weight & 0.1667 & 0.3333 & 0.5000 \\
\hline
\end{tabular}

In order to evaluate the weight of four classes, the categories of the global weight of eleven metrics and the result have been displayed in Table 8 .

Table 8. The global weights of the eleven criteria's

\begin{tabular}{|l|l|l|l|l|l|l|l|l|l|l|l|}
\hline Criteria & C1 & C2 & C3 & E1 & E2 & E3 & EE1 & EE2 & EE3 & T1 & T2 \\
\hline Weight & 0.125 & 0.1875 & 0.0625 & 0.0694 & 0.1041 & 0.0347 & 0.0208 & 0.0416 & 0.0625 & 0.2187 & 0.073 \\
\hline
\end{tabular}

To grade different nanoparticles, administrators utilized the linguistic variable firstly, to each of the matrix for sustainability assessment by involving full team expertise and researchers. The results have been encapsulated in Table 9. 
Table 9. The interpretation of the five nanoparticles using linguistic variables

\begin{tabular}{|c|c|c|c|c|c|}
\hline & A1 & $\mathrm{A} 2$ & A3 & A4 & A5 \\
\hline $\mathrm{C} 1$ & $\mathrm{~F}$ & $M P$ & MG & $\mathrm{P}$ & VP \\
\hline $\mathrm{C} 2$ & $\mathrm{~F}$ & $\mathrm{MP}$ & G & MG & $\mathrm{P}$ \\
\hline C3 & $\mathrm{MP}$ & $\mathrm{P}$ & $\mathrm{F}$ & MG & $\mathrm{G}$ \\
\hline E1 & VP & EP & MP & $P$ & $\mathrm{~F}$ \\
\hline E2 & $\mathrm{MP}$ & $\mathrm{F}$ & G & MG & $\mathrm{P}$ \\
\hline E3 & $\mathrm{P}$ & EP & $\mathrm{MP}$ & $\mathrm{P}$ & VP \\
\hline EE1 & VG & $\mathrm{EG}$ & G & MG & $\mathrm{P}$ \\
\hline EE2 & VG & $\mathrm{EG}$ & MG & $\mathrm{G}$ & $P$ \\
\hline EE3 & G & VG & MG & $\mathrm{F}$ & $\mathrm{F}$ \\
\hline $\mathrm{T} 1$ & MG & $\mathrm{MP}$ & $\mathrm{F}$ & $\mathrm{F}$ & $\mathrm{P}$ \\
\hline $\mathrm{T} 2$ & $\mathrm{EG}$ & VG & MG & $\mathrm{G}$ & $\mathrm{F}$ \\
\hline
\end{tabular}

After that, linguistic variables have been converted into $\beta$ according to Table 1 . For example, "EG, VG......VP, EP" in Table 9. can be rearranged into " $(0.95,0.05,0)(0.85,0.10,0.05) \ldots . .(0.15,0.80,0.05)(0.05,0.95,0)$ ", and shown in Table 10.

Table 10. Performances of four energy storage technologies

\begin{tabular}{|c|c|c|c|c|c|}
\hline & $\mathrm{A} 1$ & $\mathrm{~A} 2$ & A3 & A4 & A5 \\
\hline C1 & $\begin{array}{l}(0.50,0.40 \\
0.10)\end{array}$ & $(0.35,0.55,0.10)$ & $\begin{array}{l}(0.65,0.25 \\
0.10)\end{array}$ & $(0.25,0.65,0.10)$ & $(0.15,0.80,0.05)$ \\
\hline $\mathrm{C} 2$ & $\begin{array}{l}(0.50,0.40, \\
0.10)\end{array}$ & $(0.35,0.55,0.10)$ & $\begin{array}{l}(0.75,0.15 \\
0.10)\end{array}$ & $(0.65,0.25,0.10)$ & $(0.25,0.65,0.10)$ \\
\hline C3 & $\begin{array}{l}(0.35,0.55 \\
0.10)\end{array}$ & $(0.25,0.65,0.10)$ & $\begin{array}{l}(0.50,0.40 \\
0.10)\end{array}$ & $(0.65,0.25,0.10)$ & $(0.75,0.15,0.10)$ \\
\hline E1 & $\begin{array}{l}(0.15,0.80, \\
0.05)\end{array}$ & $(0.05,0.95,0)$ & $\begin{array}{l}(0.35,0.55 \\
0.10)\end{array}$ & $(0.25,0.65,0.10)$ & $(0.50,0.40,0.10)$ \\
\hline E2 & $\begin{array}{l}(0.35,0.55, \\
0.10)\end{array}$ & $(0.50,0.40,0.10)$ & $\begin{array}{l}(0.75,0.15 \\
0.10)\end{array}$ & $(0.65,0.25,0.10)$ & $(0.25,0.65,0.10)$ \\
\hline E3 & $\begin{array}{l}(0.25,0.65, \\
0.10)\end{array}$ & $(0.05,0.95,0)$ & $\begin{array}{l}(0.35,0.55 \\
0.10)\end{array}$ & $(0.25,0.65,0.10)$ & $(0.15,0.80,0.05)$ \\
\hline EE1 & $\begin{array}{l}(0.85,0.10, \\
0.05)\end{array}$ & $(0.95,0.05,0)$ & $\begin{array}{l}(0.75,0.15 \\
0.10)\end{array}$ & $(0.65,0.25,0.10)$ & $(0.25,0.65,0.10)$ \\
\hline EE2 & $\begin{array}{l}(0.85,0.10, \\
0.05)\end{array}$ & $(0.95,0.05,0)$ & $\begin{array}{l}(0.65,0.25, \\
0.10)\end{array}$ & $(0.75,0.15,0.10)$ & $(0.25,0.65,0.10)$ \\
\hline EE3 & $\begin{array}{l}(0.75,0.15 \\
0.10)\end{array}$ & $(0.85,0.10,0.05)$ & $\begin{array}{l}(0.65,0.25 \\
0.10)\end{array}$ & $(0.50,0.40,0.10)$ & $(0.50,0.40,0.10)$ \\
\hline T1 & $\begin{array}{l}(0.65,0.25, \\
0.10)\end{array}$ & $(0.35,0.55,0.10)$ & $\begin{array}{l}(0.50,0.40, \\
0.10)\end{array}$ & $(0.50,0.40,0.10)$ & $(0.25,0.65,0.10)$ \\
\hline $\mathrm{T} 2$ & $(0.95,0.05,0)$ & $(0.85,0.10,0.05)$ & $\begin{array}{l}(0.65,0.25 \\
0.10)\end{array}$ & $(0.75,0.15,0.10)$ & $(0.50,0.40,0.10)$ \\
\hline
\end{tabular}

The weighted intuitionistic fuzzy decision-making matrix is determined by Equation (27). Suppose that the element " $(0.50,0.40,0.10)$ " in cell $(1,1)$ which show metal-based nanoparticles (A1) in favour of capital cost (C1) 
(55)

$$
\begin{aligned}
& w d_{11}=\left(\mu_{11}, v_{11}, \pi_{11}\right)=\omega_{1}\left(\mu_{11}^{*}, v_{11}^{*}, \pi_{11}^{*}\right) \\
& w d_{11}=\left[\left(1-\left(1-\mu_{11}^{*}\right)^{\omega 1}\right),\left(v_{11}^{*}\right)^{\omega 1},\left(\left(1-\mu_{11}^{*}\right)^{\omega 1}-\left(v_{11}^{*}\right)^{\omega 1}\right)\right] \\
& w d_{11}=\left[\left(1-(1-0.50)^{0.1249}\right),(0.40)^{0.1249},\left((1-0.50)^{0.1249}-(0.40)^{0.1249}\right)\right] \\
& \quad \operatorname{wd}_{11}=(0.0829,0.8918,0.0252)
\end{aligned}
$$

where $\mathrm{wd}_{11}$ is first cell of Table 11.

Similarly, all cells of institution fuzzy numbers are transformed to weighted institution fuzzy decision making metrics and represented in Table 11.

Table 11. The weighted intuitionistic fuzzy decision-making matrix

\begin{tabular}{|l|l|l|l|l|l|}
\hline & A1 & A2 & A3 & A4 & A5 \\
\hline \multirow{2}{*}{ C1 } & $(0.0829,0.8918$, & $(0.0523,0.9280$, & $(0.1228,0.8410$, & $(0.0352,0.9476$, & $(0.0201,0.9725$, \\
& $0.0252)$ & $0.0195)$ & $0.0360)$ & $0.0170)$ & $0.0073)$ \\
\hline \multirow{2}{*}{ C2 } & $(0.1218,0.8421$, & $(0.0775,0.8939$, & $(0.2288,0.7006$, & $(0.1786,0.7712$, & $(0.0525,0.9224$, \\
& $0.0359)$ & $0.0284)$ & $0.0704)$ & $0.0502)$ & $0.0250)$ \\
\hline \multirow{2}{*}{ C3 } & $(0.0265,0.9634$, & $(0.0178,0.9734$, & $(0.0423,0.9443$, & $(0.0635,0.9170$, & $(0.0829,0.8881$, \\
& $0.0102)$ & $0.0087)$ & $0.0132)$ & $0.0194)$ & $0.0288)$ \\
\hline \multirow{2}{*}{ E1 } & $(0.0112,0.9846$, & $(0.0035,0.9964$, & $(0.0294,0.9593$, & $(0.0197,0.9705$, & $(0.0469,0.9383$, \\
& $0.0042)$ & $0)$ & $0.0112)$ & $0.0096)$ & $0.0146)$ \\
\hline \multirow{2}{*}{ E2 } & $(0.0438,0.9562,0)$ & $(0.0696,0.9090$, & $(0.1343,0.8207$, & $(0.1035,0.8656$, & $(0.0295,0.9561$, \\
& $0.0213)$ & $0.0448)$ & $0.0308)$ & $0.0143)$ \\
\hline \multirow{2}{*}{ E3 } & $(0.0099,0.9851$, & $(0.0017,0.9982$, & $(0.0148,0.9794$, & $(0.0099,0.9851$, & $(0.0056,0.9922$, \\
& $0.0049)$ & $0)$ & $0.0056)$ & $0.0049)$ & $0.0020)$ \\
\hline \multirow{2}{*}{ EN1 } & $0.0386,0.9532$, & $(0.0604,0.9395$, & $(0.0284,0.9613$, & $(0.0215,0.9715$, & $(0.0059,0.9910$, \\
& $0.0080)$ & $0)$ & $0.0102)$ & $0.0068)$ & $0.0029)$ \\
\hline \multirow{2}{*}{ EN2 } & $(0.0758,0.9086$, & $(0.1171,0.8828$, & $(0.0427,0.9439$, & $(0.0560,0.9241$, & $(0.0118,0.9822$, \\
& $0.0154)$ & $0)$ & $0.0134)$ & $0.0198)$ & $0.0058)$ \\
\hline \multirow{2}{*}{ EN3 } & $(0.0829,0.8881$, & $(0.1118,0.8659$, & $(0.0635,0.9171$, & $(0.0423,0.9443$, & $(0.0423,0.9443$, \\
& $0.0288)$ & $0.0223)$ & $0.0194)$ & $0.0132)$ & $0.0132)$ \\
\hline \multirow{2}{*}{ T1 } & $(0.2051,0.7384$, & $(0.0899,0.8774$, & $(0.1406,0.8184$, & $(0.1406,0.8184$, & $(0.0609,0.9101$, \\
& $0.0563)$ & $0.0326)$ & $0.0409)$ & $0.0409)$ & $0.0289)$ \\
\hline \multirow{2}{*}{ T2 } & $(0.1961,0.8038,0)$ & $(0.1291,0.8454$, & $(0.0736,0.9038$, & $(0.0961,0.8708$, & $(0.0492,0.9353$, \\
& & $0.0253)$ & $0.0224)$ & $0.0330)$ & $0.0153)$ \\
\hline
\end{tabular}

The relative interpretation of five different nanoparticles $(A 1, A 2, A 3, A 4$, and $A 5)$ with respect to $C 1$ are $(0.0829$, $0.8918,0.0252),(0.0523,0.9280,0.0195),(0.1228,0.8410,0.0360),(0.0352,0.9476,0.0170)$ and $(0.0201$, $0.9725,0.0073)$, respectively. According to Equation (27), it could be obtained that

$$
\mathrm{t}=\underset{i=1,2,3,4.5}{\operatorname{argmin}}(0.0829,0.0523,0.1228,0.0352,0.0201)=5
$$

Then, the three elements in the NIS in favour of $\mathrm{C} 1$ can be evaluated:

$$
\begin{array}{r}
\mu_{j}=\mu_{5 j}=0.0201 \\
\mathrm{v}_{j}=\mathrm{v}_{5 j}=0.9725
\end{array}
$$


(59)

$$
\pi_{j}=1-\mu_{5 j}-v_{5 j}=1-0.0201-0.9725=0.0073
$$

Similarly, all the NIS of nanoparticles have been expressed in Table 12.

Table 12. The weighted intuitionistic fuzzy decision-making matrix

\begin{tabular}{|l|l|l|l|}
\hline Criteria's & & NIS & \\
\hline C1 & 0.0201 & 0.9725 & 0.0073 \\
\hline C2 & 0.0525 & 0.9224 & 0.0250 \\
\hline C3 & 0.0178 & 0.9734 & 0.0087 \\
\hline E1 & 0.0035 & 0.9964 & 0 \\
\hline E2 & 0.0295 & 0.9561 & 0.014 \\
\hline E3 & 0.0017 & 0.9982 & 0 \\
\hline EE1 & 0.0059 & 0.9910 & 0.0029 \\
\hline EE2 & 0.0118 & 0.9822 & 0.0058 \\
\hline EE3 & 0.0423 & 0.9443 & 0.0132 \\
\hline T1 & 0.0609 & 0.9100 & 0.0289 \\
\hline T2 & 0.0492 & 0.9353 & 0.0153 \\
\hline
\end{tabular}

After the determination of the NIS, we have to find the Euclidean and Hamming distance for each nanoparticle from NIS as expressed in Equations $(33,34)$ and result as shown in Table 13.

Table 13. Euclidean and Hamming distance

\begin{tabular}{|l|l|l|}
\hline & $E i$ & \multicolumn{1}{c|}{$H i$} \\
\hline 1 & 0.3612 & 1.333 \\
\hline 2 & 0.2502 & 0.9437 \\
\hline 3 & 0.4088 & 1.5841 \\
\hline 4 & 0.2979 & 1.1919 \\
\hline
\end{tabular}

The relative assessment matrix as presented in Equation (61) has been determined using Equations (35) to (37) by taking threshold value $(\tau)$ as 0.05 . 
(60)

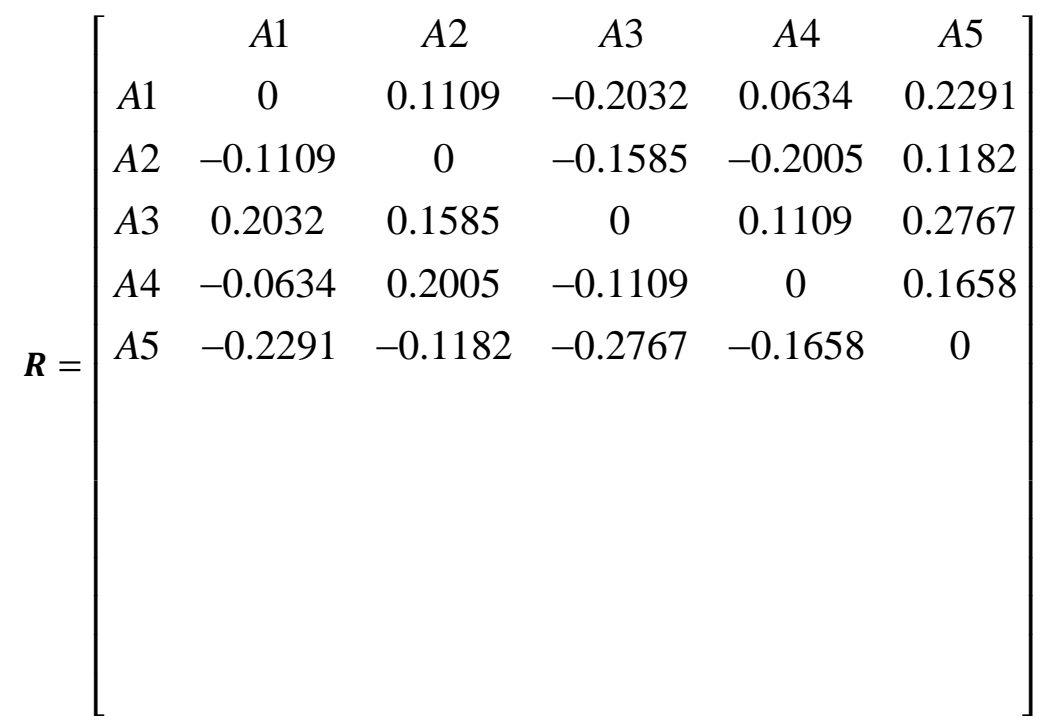

Then, the final assessment score of each nanoparticle have been determined using Equation (38) and as shown in Equations (61) to (65).

$$
\begin{gathered}
S_{1}=0+0.1109+(-0.2032)+0.0634+0.2291=0.2002 \\
S_{2}=(-0.1109)+0+(-0.1585)+(-0.2005)+0.1182=-0.3517 \\
S_{3}=0.2032+0.1585+0+0.1109+0.2767=0.7493 \\
S_{4}=(-0.0634)+0.2005+(-0.1109)+0+0.1658=0.1920 \\
S_{5}=(-0.2291)+(-0.1182)+(-0.2767)+(-0.1658)+0=-0.7898
\end{gathered}
$$

As per the final assessment scores of the five nanoparticles, the carbon based (A3) has been identified as the most sustainable one, followed by metal based (A1), polymeric (A4),ceramic (A2), and lipid based (A5) from the outmost sustainable one to the least sustainable. The outcome of distinguishing carbon based has been established to be the most sustainable.

\section{Results and discussion}

For the ranking of five nanoparticles, the single criterion has been used as per relative interpretation on each of the eleven criteria. The prescription of the single criterion analysis method is as follows:

Assume that $\gamma=\left(\mu_{\gamma}, v_{\gamma}, \pi_{\gamma}\right)$ and $\beta=\left(\mu_{\beta}, v_{\beta}, \pi_{\beta}\right)$ are two $\beta$ s to characterize the relative interpretation of two alternative nanoparticles $A$ and $B$ on an estimation benchmark, respectively. The highly superior nanoparticle between $A$ and $B$ alternatives can be resolved as per the following rules.

1) If $R_{\gamma}=\mu_{\gamma}-v_{\gamma}<R_{\beta}=\mu_{\beta}-v_{\beta}$ then $\gamma=\left(\mu_{\gamma}, v_{\gamma}, \pi_{\gamma}\right)$ is smaller than $\beta=\left(\mu_{\beta}, v_{\beta}, \pi_{\beta}\right)$ and $\mathrm{A}$ is inferior to $\mathrm{B}$.

2) If $R_{\gamma}=\mu_{\gamma}-v_{\gamma}<R_{\beta}=\mu_{\beta}-v_{\beta}$, than;

a. $r_{\gamma}=\mu_{\gamma}+v_{\gamma}=r_{\beta}=\mu_{\beta}+v_{\beta}$, then, $\gamma=\left(\mu_{\gamma}, v_{\gamma}, \pi_{\gamma}\right)$ is equal to $\beta=\left(\mu_{\beta}, v_{\beta}, \pi_{\beta}\right)$, and $\mathrm{A}$ is indifferent to $\mathrm{B}$;

b. $r_{\gamma}=\mu_{\gamma}+v_{\gamma}<r_{\beta}=\mu_{\beta}+v_{\beta}$, then, $\gamma=\left(\mu_{\gamma}, v_{\gamma}, \pi_{\gamma}\right)$ is smaller than $\beta=\left(\mu_{\beta}, v_{\beta}, \pi_{\beta}\right)$, and $\mathrm{A}$ is inferior to $\mathrm{B}$; 
c. $r_{\gamma}=\mu_{\gamma}+v_{\gamma}>r_{\beta}=\mu_{\beta}+v_{\beta}$, then, $\gamma=\left(\mu_{\gamma}, v_{\gamma}, \pi_{\gamma}\right)$ is greater than $\beta=\left(\mu_{\beta}, v_{\beta}, \pi_{\beta}\right)$, and $\mathrm{A}$ is superior to $\mathrm{B}$;

where $R_{\gamma}$ and $R_{\beta}$ epitomize the scores of the intuitionistic fuzzy sets, $\gamma=\left(\mu_{\gamma}, v_{\gamma}, \pi_{\gamma}\right)$ and $\beta=\left(\mu_{\beta}, v_{\beta}, \pi_{\beta}\right)$, respectively $r_{\gamma}$ and $r_{\beta}$ are the accuracy in intuitionistic fuzzy sets, $\gamma=\left(\mu_{\gamma}, v_{\gamma}, \pi_{\gamma}\right)$ and $\beta=\left(\mu_{\beta}, v_{\beta}, \pi_{\beta}\right)$, respectively.

For the ranking of five substitute nanoparticles, Table 14 and Fig. 2 has been presented on the basis of the results of single-criterion method. It is clearly visible that the positioning of these five nanoparticles based on contrasting criterion is divergent. Thus, the administrator necessitates the unique sustainability sequence of individual substitute aggregating the execution order of these five alternatives on eleven evaluation criteria into generic content which helps the administrators to accomplish their objective.

Value of $\tau$ is distorted to discover the dissimilarity of the sustainability ranking of the five alternative nanoparticles because of threshold value influence, and the results have been presented in Table 15.

Table 14. The ranking of the five nanofluids using the single-criterion analysis method.

\begin{tabular}{|c|c|c|c|c|c|}
\hline & A1 & $A 2$ & A3 & A4 & A5 \\
\hline C1 & 4 & 2 & 3 & 5 & 1 \\
\hline $\mathrm{C} 2$ & 5 & 1 & 4 & 3 & 2 \\
\hline C3 & 5 & 3 & 2 & 1 & 4 \\
\hline E1 & 5 & 1 & 4 & 2 & 3 \\
\hline E2 & 2 & 1 & 4 & 3 & 5 \\
\hline E3 & 3 & 1 & 5 & 4 & 2 \\
\hline EN1 & 5 & 1 & 3 & 4 & 2 \\
\hline EN2 & 4 & 2 & 3 & 5 & 1 \\
\hline EN3 & 4 & 2 & 3 & 5 & 1 \\
\hline $\mathrm{T} 1$ & 3 & 2 & 5 & 4 & 1 \\
\hline $\mathrm{T} 2$ & 1 & 5 & 2 & 4 & 5 \\
\hline
\end{tabular}

Table 15. The results of the analysis of the threshold value on the sustainability ranking of the five nanoparticles

\begin{tabular}{|llllll|}
\hline & A1 & A2 & A3 & A4 & A5 \\
\hline Final assessment score & 0.2002 & -0.3517 & 0.7493 & 0.1920 & -0.7898 \\
\hline Ranking & 2 & 4 & 1 & 3 & 5 \\
\hline
\end{tabular}




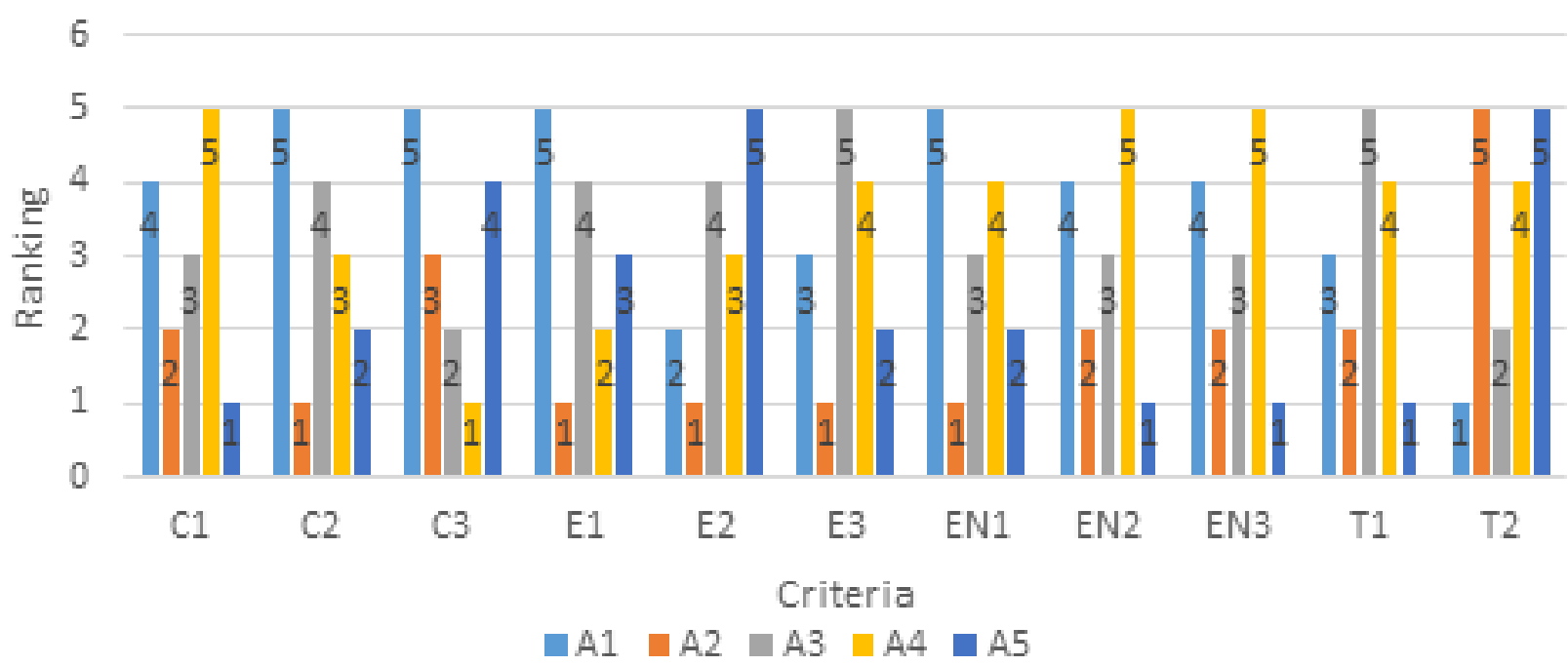

Fig. 2. Ranking of criteria for different nanoparticles

Impact

The present analysis of a heat exchanger with nanomaterial as working fluid is carried using the intuitionistic fuzzy combative distance-based assessment (IFCODAS) in collaboration with Intuitionistic fuzzy set (IFS). The major aim is to determine the sustainability of nanoparticles in the system. The results reveal that carbon-based nanoparticles significantly provide the reliable and sustainable thermal system than other nanoparticles. This type of assessment approach will lead to the development of an effective system that works with the best suited parameters. The determination of reliable and sustainable parameter of a system will make is economically viable and trustworthy, that will lead to utilization of the resources to full extent as well as the present technique will lead to find out the dominating parameters without much focusing on the experimental processes, as it will provide a dominating value for a parameter. The real practical application of this model will lead to practically reducing the number of experimental runs and thus will fetch benefit in time saving and monetary as well. Apart from this the evaluation criterions consist of environmental aspect that will suggest the best suited nanomaterial that does not raises the environmental concern. The present analysis will lead to figure out the nanoparticle usage on the basis of environmental effect and will lead to develop a reliable system design of a heat exchanger. Beside the number of advantages, a setback in this system is the complexity of the design that is used to study the focused parameter on the basis of selected criterions.

\section{Conclusion}

A fresh model of suitability of nanoparticles scheme to grasp multi-criteria decision-making problems has been foreshadowed in the present study. Multi-criteria decision-making (MCDM) has been progressively applied to numerous real-world predicaments. Several methods and techniques in order to cope up with the quandaries to handle multi-criteria decision-making problems have been proposed by the researchers. The proposed method intends to evaluate the alternatives, five nanoparticles (carbon based, ceramic, metal nanoparticles, polymeric, and lipid) with the help of intuitionistic fuzzy combative distance-based assessment method by giving them ranking on the basis of their assessment. Discussing absolute judgment scores of various nanoparticles, the most sustainable resulted in carbon based (A3). Amongst the five nanoparticles, carbon-based nanoparticle has been found to the most sustainable owing to the reason that the carbon-based nanoparticle is composed of unpolluted carbons and holds astounding mechanical properties, electrical conductivity and heat conductivity with pure carbons, consequently demonstrating ecological gregariousness, superior conductivity, heat steadiness, and stumpy toxicity. It can thus be stated that the projected method is proficient in order to deal with MCDM impediments, as held in unison with the results of this study.

\section{Conflict of interest}

There are no conflicts to declare.

\section{Acknowledgments}

This research has not been supported by any external funding. 


\section{References}

[1] T.R. Kiran, S.P.S. Rajput, An effectiveness model for an indirect evaporative cooling (IEC) system: Comparison of artificial neural networks (ANN), adaptive neuro-fuzzy inference system (ANFIS) and fuzzy inference system (FIS) approach, Appl. Soft Comput. J. 11 (2011) 3525-3533. https://doi.org/10.1016/j.asoc.2011.01.025.

[2] O.A. Akbari, H.H. Afrouzi, A. Marzban, D. Toghraie, H. Malekzade, A. Arabpour, Investigation of volume fraction of nanoparticles effect and aspect ratio of the twisted tape in the tube, J. Therm. Anal. Calorim. 129 (2017) 1911-1922. https://doi.org/10.1007/s10973-017-6372-7.

[3] W.H. Azmi, K. V. Sharma, P.K. Sarma, R. Mamat, S. Anuar, Comparison of convective heat transfer coefficient and friction factor of TiO2 nanofluid flow in a tube with twisted tape inserts, Int. J. Therm. Sci. 81 (2014) 84-93. https://doi.org/10.1016/j.ijthermalsci.2014.03.002.

[4] S.S. Chougule, S.K. Sahu, Heat transfer and friction characteristics of Al2O3/water and CNT/water nanofluids in transition flow using helical screw tape inserts - a comparative study, Chem. Eng. Process. Process Intensif. 88 (2015) 78-88. https://doi.org/10.1016/j.cep.2014.12.005.

[5] S. Eiamsa-Ard, K. Wongcharee, Single-phase heat transfer of CuO/water nanofluids in micro-fin tube equipped with dual twisted-tapes, Int. Commun. Heat Mass Transf. 39 (2012) 1453-1459. https://doi.org/10.1016/j.icheatmasstransfer.2012.08.007.

[6] S. Eiamsa-Ard, K. Kiatkittipong, Heat transfer enhancement by multiple twisted tape inserts and TiO 2/water nanofluid, Appl. Therm. $\quad$ Eng. $70 \quad$ (2014) 896-924. https://doi.org/10.1016/j.applthermaleng.2014.05.062.

[7] R. Hosseinnezhad, O.A. Akbari, H. Hassanzadeh Afrouzi, M. Biglarian, A. Koveiti, D. Toghraie, Numerical study of turbulent nanofluid heat transfer in a tubular heat exchanger with twin twisted-tape inserts, J. Therm. Anal. Calorim. 132 (2018) 741-759. https://doi.org/10.1007/s10973-017-6900-5.

[8] M. Jafaryar, M. Sheikholeslami, Z. Li, CuO-water nanofluid flow and heat transfer in a heat exchanger tube with twisted tape turbulator, Powder Technol. $336 \quad$ (2018) 131-143. https://doi.org/10.1016/j.powtec.2018.05.057.

[9] D. MageshBabu, P.K. Nagarajan, R. Sathyamurthy, S.S.J. Krishnan, Enhancing the thermal performance of AL2O3/DI water nanofluids in micro-fin tube equipped with straight and left-right twisted tapes in turbulent flow regime, Exp. Heat Transf. $30 \quad$ (2017) 267-283. https://doi.org/10.1080/08916152.2016.1238857.

[10] H. Mohammadiun, M. Mohammadiun, M. Hazbehian, H. Maddah, Experimental study of ethylene glycolbased Al2O3 nanofluid turbulent heat transfer enhancement in the corrugated tube with twisted tapes, Heat Mass Transf. Und Stoffuebertragung. 52 (2016) 141-151. https://doi.org/10.1007/s00231-0151550-2.

[11] M.T. Naik, G.R. Janardana, L.S. Sundar, Experimental investigation of heat transfer and friction factor with water-propylene glycol based $\mathrm{CuO}$ nanofluid in a tube with twisted tape inserts, Int. Commun. Heat Mass Transf. 46 (2013) 13-21. https://doi.org/10.1016/j.icheatmasstransfer.2013.05.007.

[12] N.T. Ravi Kumar, P. Bhramara, A. Kirubeil, L. Syam Sundar, M.K. Singh, A.C.M. Sousa, Effect of twisted tape inserts on heat transfer, friction factor of Fe304 nanofluids flow in a double pipe U-bend heat exchanger, Int. Commun. Heat Mass Transf. $95 \quad$ (2018) 53-62. https://doi.org/10.1016/j.icheatmasstransfer.2018.03.020.

[13] J. Deng, M. Wang, J. Fang, X. Song, Z. Yang, Z. Yuan, Synthesis of Zn-doped TiO2 nano-particles using metal $\mathrm{Ti}$ and $\mathrm{Zn}$ as raw materials and application in quantum dot sensitized solar cells, J. Alloys Compd. 791 (2019) 371-379. https://doi.org/10.1016/j.jallcom.2019.03.306.

[14] X. Liu, J. Wang, Y.W. Huang, T. Kong, Algae (Raphidocelis) reduce combined toxicity of nano-TiO2 and lead on C. dubia, Sci. Total Environ. $686 \quad$ (2019) 246-253. https://doi.org/10.1016/j.scitotenv.2019.06.033.

[15] S. Fukuzumi, Y. Yamada, Catalytic activity of metal-based nanoparticles for photocatalytic water oxidation and reduction, J. Mater. Chem. 22 (2012) 24284-24296. https://doi.org/10.1039/c2jm32926c.

[16] R. D’Amato, M. Falconieri, S. Gagliardi, E. Popovici, E. Serra, G. Terranova, E. Borsella, Synthesis of ceramic nanoparticles by laser pyrolysis: From research to applications, J. Anal. Appl. Pyrolysis. 104 (2013) 461-469. https://doi.org/10.1016/j.jaap.2013.05.026.

[17] D. Vollath, D.V. Szabó, J. Haußelt, Synthesis and properties of ceramic nanoparticles and nanocomposites, J. Eur. Ceram. Soc. 17 (1997) 1317-1324. https://doi.org/10.1016/s09552219(96)00224-5.

[18] K. Matsumoto, H. Matsuoka, Synthesis of core-crosslinked carbosilane block copolymer micelles and their thermal transformation to silicon-based ceramics nanoparticles, J. Polym. Sci. Part A Polym. Chem. 
43 (2005) 3778-3787. https://doi.org/10.1002/pola.20879.

[19] J. Shen, L. Dudik, C.C. Liu, An iridium nanoparticles dispersed carbon based thick film electrochemical biosensor and its application for a single use, disposable glucose biosensor, Sensors Actuators, B Chem. 125 (2007) 106-113. https://doi.org/10.1016/j.snb.2007.01.043.

[20] J. Zhou, T. Zhu, W. Xing, Z. Li, H. Shen, S. Zhuo, Activated polyaniline-based carbon nanoparticles for high performance supercapacitors, Electrochim. Acta. $160 \quad$ (2015) $152-159$. https://doi.org/10.1016/j.electacta.2015.02.032.

[21] J.M. Ngoy, N. Wagner, L. Riboldi, O. Bolland, A CO2 capture technology using multi-walled carbon nanotubes with polyaspartamide surfactant, in: Energy Procedia, 2014: pp. 2230-2248. https://doi.org/10.1016/j.egypro.2014.11.242.

[22] Y. Zhang, D. Petibone, Y. Xu, M. Mahmood, A. Karmakar, D. Casciano, S. Ali, A.S. Biris, Toxicity and efficacy of carbon nanotubes and graphene: The utility of carbon-based nanoparticles in nanomedicine, Drug Metab. Rev. 46 (2014) 232-246. https://doi.org/10.3109/03602532.2014.883406.

[23] C. He, Y. Hu, L. Yin, C. Tang, C. Yin, Effects of particle size and surface charge on cellular uptake and biodistribution of polymeric nanoparticles, Biomaterials. $31 \quad$ (2010) 3657-3666. https://doi.org/10.1016/j.biomaterials.2010.01.065.

[24] L.A. Zadeh, Fuzzy sets, Inf. Control. 8 (1965) 338-353. https://doi.org/10.1016/S0019-9958(65)90241-X.

[25] K.T. Atanassov, Intuitionistic fuzzy sets, Fuzzy Sets Syst. 20 (1986) 87-96. https://doi.org/10.1016/S01650114(86)80034-3.

[26] Z. Xu, R.R. Yager, Some geometric aggregation operators based on intuitionistic fuzzy sets, Int. J. Gen. Syst. 35 (2006) 417-433. https://doi.org/10.1080/03081070600574353.

[27] E. Szmidt, J. Kacprzyk, Distances between intuitionistic fuzzy sets, Fuzzy Sets Syst. 114 (2000) 505-518. https://doi.org/10.1016/S0165-0114(98)00244-9.

[28] D.H. Hong, C.H. Choi, Multicriteria fuzzy decision-making problems based on vague set theory, Fuzzy Sets Syst. 114 (2000) 103-113. https://doi.org/10.1016/S0165-0114(98)00271-1.

[29] J. Ren, D. Xu, H. Cao, S. Wei, L. Dong, M.E. Goodsite, Sustainability decision support framework for industrial system prioritization, AIChE J. 62 (2016) 108-130. https://doi.org/10.1002/aic.15039.

[30] J. Ren, X. Ren, Sustainability ranking of energy storage technologies under uncertainties, J. Clean. Prod. 170 (2018) 1387-1398. https://doi.org/10.1016/j.jclepro.2017.09.229.

[31] X.Z. Shui, D.Q. Li, A possibility based method for priorities of interval judgment matrix, Chinese J. Manag. Sci. 11 (2003) 63-65.

[32] T.L. Saaty, Decision making with the Analytic Hierarchy Process, Sci. Iran. 9 (2002) 215-229. https://doi.org/10.1504/ijssci.2008.017590.

[33] J. Ren, X. Ren, H. Liang, L. Dong, L. Zhang, X. Luo, Y. Yang, Z. Gao, Multi-actor multi-criteria sustainability assessment framework for energy and industrial systems in life cycle perspective under uncertainties. Part 2: improved extension theory, Int. J. Life Cycle Assess. 22 (2017) 1406-1417. https://doi.org/10.1007/s11367-016-1252-0.

[34] M. Keshavarz Ghorabaee, E.K. Zavadskas, Z. Turskis, J. Antucheviciene, A new combinative distancebased assessment (CODAS) method for multi-criteria decision-making, Econ. Comput. Econ. Cybern. Stud. Res. 50 (2016) 25-44.

[35] S. Pramanik, D. Mukhopadhyaya, Grey relational analysis based intuitionistic fuzzy multi-criteria group decision-making approach for teacher selection in Higher Education, Int. J. Comput. Appl. 34 (2011) 2129. https://doi.org/10.5120/4138-5985.

[36] Z. Xu, Intuitionistic fuzzy aggregation operators, IEEE Trans. Fuzzy Syst. 15 (2007) 1179-1187. https://doi.org/10.1109/TFUZZ.2006.890678. 